\title{
Mycobacterium fortuitum Complex
}

National Cancer Institute

\section{Source}

National Cancer Institute. Mycobacterium fortuitum Complex. NCI Thesaurus. Code C86539.

A non taxonomic grouping of bacteria assigned to and including related species from the Mycobacterium genus not including those bacteria in the Mycobacterium tuberculosis complex. 